\title{
Perceptions of veterinarians and producers concerning Johne's disease prevalence and control in US beef cow-calf operations
}

\author{
Bikash Bhattarai ${ }^{1,6^{*}}$, Geoffrey T Fosgate ${ }^{2}$, Jason B Osterstock ${ }^{3}$, Seong C Park ${ }^{4}$ and Allen J Rousse ${ }^{5}$
}

\begin{abstract}
Background: Efforts to educate producers and veterinarians in the United States regarding the management, prevention and control of Mycobacterium avium subspecies paratuberculosis (MAP) infection have increased over recent years. While nationwide awareness about MAP infection is improving, current level of awareness among beef producers and veterinarians is largely unknown. This study compares the perceptions of beef producers and veterinarians on the burden of MAP infection in cow-calf herds and on measures to control new infections. Questionnaires were mailed to 989 US beef producers through state Designated Johne's Coordinators and to 1080 bovine veterinarians belonging to a US nationwide professional association.

Results: Twenty-two percent (34/155) of producers reported having infected animals in their herds. The mean (minimum, median, maximum) prevalence reported by producers was $0.8 \%(0,0,10)$. Twenty-seven percent $(27 / 100)$ of producers had at least one clinical animal during the previous year. Compared to the small herds ( $<50$ head), the mean test-positive percentages and estimated prevalences were higher in medium (50-149) and highest in large $(\geq 150)$ herds. Seedstock herds had a lower prevalence and these producers were more likely to enroll in Johne's disease (JD) control programs and test their herds. Veterinarians reported a mean overall animal level prevalence in their client herds of $5 \%(0,2,60)$. Similarly, $26 \%(0,10,100)$ of client herds had at least one infected animal. Mean percentage of infected cows within infected herds was $9 \%(0.01,5,80)$. Producers generally performed activities to control MAP transmission more frequently than perceived by veterinarians. Compared to veterinarians' opinions, producers were less likely to cull cows with signs consistent with JD $(P<0.01)$, but more likely to test purchased additions $(P<0.01)$. Testing recommendations by veterinarians $(n=277)$ for beef cow-calf herds were bacterial culture of feces $(3 \%), P C R(14 \%)$, ELISA (35\%) and a combination of these tests (47\%). Seventy-nine percent of veterinarians recommended a 12-month interval between testing.

Conclusions: Seedstock producers who had had JD risk assessments performed on their farms were more supportive of JD control programs and had a correspondingly lower prevalence. It is important to increase educational activities to provide relevant information to veterinarians and producers for better management and control of JD. Educational programs should target larger herds to maximize the impact.
\end{abstract}

Keywords: Johne's disease, Beef cattle, Mycobacterium avium subspecies paratuberculosis

\footnotetext{
* Correspondence: Bikash_Bhattarai@baylor.edu

'Department of Veterinary Integrative Biosciences, Texas A\&M University,

College Station, TX 77843, USA

${ }^{6}$ Current address: Institute of Biomedical Studies, Baylor University, One Bear

Place, Box 97261, Waco, TX 76798, USA

Full list of author information is available at the end of the article
} 


\section{Background}

Mycobacterium avium subsp. paratuberculosis (MAP) is the etiologic agent associated with bovine paratuberculosis, which is commonly known as Johne's disease (JD). In cattle, JD is characterized by a chronic granulomatous ileocolitis, a long pre-clinical phase terminating in diarrhea, debilitation [1,2], cachexia and death [3]. Reported prevalence estimates of MAP infected beef cattle in the United States vary widely, ranging from $0.4 \%$ to $9 \%$ of animals and $8 \%$ to $63 \%$ of herds based on detection of MAPspecific serum antibodies [4-8].

The Beef' ' 97 and Beef 2007-08 studies by the National Animal Health Monitoring System (NAHMS) estimated that $92 \%$ and $69 \%$, respectively, of beef producers were unaware of JD or only recognized the name without having direct knowledge about the disease [4]. The United States Voluntary Bovine JD Control Program (VBJDCP) was implemented since 2003 to provide minimum national standards for the control of JD and to educate veterinarians and producers regarding management, prevention and control of JD [9]. A survey in Texas during 2006 suggested that only $20 \%$ of beef producers were familiar with the VBJDCP and 16\% considered participation [10]. Sixty-four percent of veterinarians in Texas had educated beef producers on management strategies for the control or elimination of JD. However, only $36 \%$ of these veterinarians had received specific training regarding JD epidemiology and 29\% were JDcertified [10].

The VBJDCP has been the official control program developed in cooperation with industry stakeholders and experts and subsequently approved by the United States Department of Agriculture. The US government provided financial support for the control program and to assist producers with risk assessments, management changes, and diagnostic testing [11]. The VBJDCP consists of three elements: education, management, and herd classification [12]. An important component of the education component is veterinarian certification through an Internet-based training. The management component is implemented by veterinarians certified to perform JD risk assessments and develop management plans. A JD risk assessment is a structured investigation of management practices based on an on-farm evaluation of risk factors and owner responses related to management practices and biosecurity $[9,13]$.

The objective of this study was to compare the perceptions of beef producers that had risk assessments and herd management plans developed for JD and bovine veterinarians on the burden of MAP infection in cow-calf herds and measures to control new infections. A secondary objective was to compare perceptions among different types of cow-calf producers and veterinarians.

\section{Methods}

The study protocol was approved by the Institutional Review Board at Texas A\&M University (protocol number 2010-06666).

\section{Questionnaire}

A mailed questionnaire was administered to beef producers in 9 US states (FL, GA, IA, MO, ND, SC, SD, WI, WV) that had risk assessments and herd management plans developed for JD. At the time of the survey, producers were either actively participating or had participated in the past in a JD control program. The Designated Johne's Coordinators of each selected state mailed questionnaires to all beef producers that had had JD risk assessments performed and herd management plans developed for JD.

Another questionnaire was mailed to veterinarians from the same 9 states with active membership in a nationwide professional organization and who listed "bovine" as one of their practice types. The majority of questions for the veterinarian and producer questionnaires were comparable. Veterinarians were contacted with an introductory letter 12 days prior to the mailing of questionnaires. A business reply envelope and a $\$ 2$ bill were included in each questionnaire packet as an incentive to improve response proportions [14]. Reminder post-cards were mailed 8 days after the questionnaire. Additional details on questionnaire development and administration have been described elsewhere [15].

\section{Analysis}

Responses from completed questionnaires were recorded on a secure server using SelectSurvey (ClassApps.com, 2006, SelectSurvey.NET 1.5.1). Data were analyzed using Stata $^{\bullet}$ (StataCorp. 2011. Stata ${ }^{\circ}$ Statistical Software: Release 11.2. College Station, TX: StataCorp LP) and OpenEpi [16]. Continuous outcomes were described using the mean, minimum, median, and maximum values. Variables were evaluated for a normal distribution using the Shapiro-Wilk test. Wilcoxon rank-sum tests were used to compare variables that were not normally distributed. Two-sided statistical tests were performed and results were interpreted at the $5 \%$ level of significance.

To account for variation in response among questions, response proportions were estimated using the number of total respondents to the specific question as the denominator. Responses regarding whether the herd was ever tested for JD or currently enrolled in any JD control program were compared between respondents with and without specific herd types. Burden of MAP infection in producer herds and veterinarian client herds were summarized and compared among types of herds. Likert scale responses concerning the frequency of selected disease control activities performed by producers and perceived by 
veterinarians were dichotomized. The "always" and "mostly" categories were collapsed into a single "yes" category and the categories "seldom" and "never" were collapsed into "no". The category "sometimes" was handled as missing data. Frequencies of these activities performed with the intent of controlling JD were evaluated using odds ratios with corresponding 95\% confidence intervals and mid-point exact $\mathrm{P}$ values. Three herd size categories were created with each group having an approximately equal number of observations: small ( $<50$ head), medium (50-149 head) and large ( $\geq 150$ head) herds.

\section{Results}

\section{Description of producers}

Questionnaires were mailed to 989 cow-calf producers. Twenty-four questionnaires were undeliverable due to incorrect addresses. The response proportion was 17\% with 160 questionnaires returned. The mean (minimum, median, maximum) herd size reported by producers was 155 head $(3,70,2500)$. Thirty-five percent $(54 / 155)$ of herds had less than 49 adult cows, 35\% (55/155) of herds had 50 to 149 cows and 30\% (46/155) of herds had 150 or more cows. Mean number of years in the cow-calf business was $32(6,32,83)$. Angus was the predominant breed reported by $52 \%(81 / 156)$ of respondents. A total of $58 \%$ of producers had commercial cow-calf herds and $56 \%$ were partially or fully comprised of purebred seedstock (Table 1).

Ninety-five percent $(149 / 157)$ of producers had tested their herds for JD at least once and 74\% (117/158) of

Table 1 Description of the herds of producers $(n=160)$ and client herds of veterinarians $(n=325)$ who responded to the Johne's disease questionnaire

\begin{tabular}{lll}
\hline Variables & Producers & Veterinarians \\
\hline Number (\%) of herd types & & \\
\hline Commercial cow calf - registered $^{\mathrm{b}}$ & $37(23.1)$ & $224(70.2)$ \\
Commercial cow-calf not registered & $64(40.0)$ & $275(86.2)$ \\
Seedstock $^{c}$ registered & $86(53.8)$ & $189(59.3)$ \\
Seedstock not registered & $10(6.3)$ & $107(33.5)$ \\
Feedlot $^{d}$ & 0 & $184(57.8)$ \\
Backgrounder $^{\mathrm{e}}$, stocker and dairy herds & 0 & $64(20.1)$ \\
Herd attributes & & \\
\hline Mean herd size (min, median, max) & $155(3,70,2500)$ & $105(0,50,3000)$ \\
Percentage of infected herds & 21.9 & 26.3 \\
Mean prevalence (min, median, max) & $0.8(0,0,10)$ & $4.8(0,2,60)$ \\
\hline
\end{tabular}

${ }^{a} \mathrm{~A}$ cow-calf herd is a beef cattle herd maintained to produce beef calves, which are usually sold after weaning

${ }^{\mathrm{b}}$ Registered herd is registered with a cattle breed association.

'Seedstock herds produce cattle of a known pedigree that are typically purebred.

${ }^{d}$ Feedlot is a feeding operation that raises beef cattle until they are finished and ready for slaughter.

${ }^{\mathrm{e}}$ Backgrounders and stockers raise calves from weaning until being sent to a feedlot. producers were currently enrolled in either the VBJDCP $(89 \%, 100 / 113)$ or had a JD control program designed by their veterinarian. The mean number of years since the inception of a control program was $7(1,6,30)$. Thirtyeight percent $(56 / 149)$ of respondents maintained a closed herd. Seedstock producers were 4 times more likely $(\mathrm{P}<0.001)$ to be currently enrolled in a JD control program compared to non-seedstock producers, despite the fact that both groups had risk assessments as defined in the survey sample frame. Enrollment was 10 times less likely $(\mathrm{P}<0.001)$ in producers with commercial cowcalf herds, and 3 times less likely $(\mathrm{P}=0.031)$ for producers with JD clinical cows (Table 2).

\section{Description of veterinarians}

Three percent $(31 / 1080)$ of mailed questionnaires were undeliverable due to incorrect addresses. A total of 382 questionnaires were returned but 57 lacked useful

Table 2 Involvement of US beef cow-calf producers in Johne's disease testing, enrollment in a control program and maintenance of a closed herd during 2010-2011

\begin{tabular}{|c|c|c|c|c|c|c|}
\hline \multicolumn{2}{|l|}{ Variable } & & & \multirow[t]{2}{*}{ Odds ratio } & \multirow[t]{2}{*}{$95 \% \mathrm{Cl}$} & \multirow[t]{2}{*}{$P^{a}$} \\
\hline Tested herd for MAP & & Yes & No & & & \\
\hline \multirow[t]{2}{*}{ Commercial cow-calf } & Yes & 85 & 7 & \multirow{2}{*}{0.19} & \multirow{2}{*}{0.02 to 1.58} & \multirow{2}{*}{0.099} \\
\hline & No & 64 & 1 & & & \\
\hline \multirow[t]{2}{*}{ Seedstock } & Yes & 86 & 3 & \multirow{2}{*}{2.28} & \multirow{2}{*}{0.52 to 9.87} & \multirow{2}{*}{0.292} \\
\hline & No & 63 & 5 & & & \\
\hline \multirow[t]{2}{*}{ Closed herds } & Yes & 52 & 4 & \multirow{2}{*}{0.59} & \multirow{2}{*}{0.14 to 2.49} & \multirow{2}{*}{0.499} \\
\hline & No & 87 & 4 & & & \\
\hline \multirow[t]{2}{*}{ With clinical cow } & Yes & 23 & 4 & \multirow{2}{*}{0.25} & \multirow{2}{*}{0.05 to 1.20} & \multirow{2}{*}{0.101} \\
\hline & No & 69 & 3 & & & \\
\hline
\end{tabular}

Enrolled in a control Yes No
program

\begin{tabular}{|c|c|c|c|c|c|c|}
\hline \multirow[t]{2}{*}{ Commercial cow-calf } & Yes & 56 & 37 & \multirow{2}{*}{0.10} & \multirow{2}{*}{0.03 to 0.30} & \multirow{2}{*}{$<0.00$} \\
\hline & No & 61 & 4 & & & \\
\hline \multirow[t]{2}{*}{ Seedstock } & Yes & 76 & 13 & \multirow{2}{*}{3.99} & \multirow{2}{*}{1.87 to 8.53} & \multirow{2}{*}{$<0.00$} \\
\hline & No & 41 & 28 & & & \\
\hline \multirow[t]{2}{*}{ Closed herds } & Yes & 42 & 14 & \multirow{2}{*}{1.12} & \multirow{2}{*}{0.52 to 2.39} & \multirow{2}{*}{0.780} \\
\hline & No & 67 & 25 & & & \\
\hline \multirow[t]{2}{*}{ With clinical cow } & Yes & 14 & 13 & \multirow{2}{*}{0.35} & \multirow{2}{*}{0.14 to 0.89} & \multirow{2}{*}{0.031} \\
\hline & No & 55 & 18 & & & \\
\hline \multicolumn{2}{|c|}{ Maintained a closed herd } & Yes & No & & & \\
\hline \multirow[t]{2}{*}{ Commercial cow-calf } & Yes & 37 & 50 & \multirow{2}{*}{1.68} & \multirow{2}{*}{0.84 to 3.33} & \multirow{2}{*}{0.145} \\
\hline & No & 19 & 43 & & & \\
\hline \multirow[t]{2}{*}{ Seedstock } & Yes & 31 & 54 & \multirow{2}{*}{0.90} & \multirow{2}{*}{0.46 to 1.75} & \multirow{2}{*}{0.749} \\
\hline & No & 25 & 39 & & & \\
\hline \multirow[t]{2}{*}{ With clinical cow } & Yes & 8 & 15 & \multirow{2}{*}{0.98} & \multirow{2}{*}{0.36 to 2.64} & \multirow{2}{*}{0.975} \\
\hline & No & 24 & 44 & & & \\
\hline
\end{tabular}

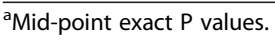


information. The most common reasons for not completing the questionnaire were that respondents were not currently involved in beef practice $(n=24)$, there were no cattle (dairy or beef) clients in the practice $(n=23)$ and the respondents were retired $(n=20)$. Twentyeight of these veterinarians also returned the $\$ 2$ incentive along with the questionnaire. Thirty-one percent of mailed questionnaires provided information that could be used for analysis.

Forty-one percent $(132 / 325)$ of veterinarians reported that they currently are or were JD certified and 38\% (121/317) had performed a JD risk assessment. Risk assessments for JD were performed by $62 \%(78 / 126)$ of JD certified veterinarians and by $22 \%(42 / 190)$ of veterinarians that had never been certified. Eighty-eight percent $(279 / 318)$ of veterinarians currently served cow-calf herds and $7 \%(22 / 318)$ of respondents had had cow-calf clients in the past. Mean number of herds served by respondents as the primary veterinarian was $58(0,30$, 1000). Mean size of herds currently served by veterinarians was $105(0,50,3000)$.

A total of $65 \%(200 / 306)$ of veterinarians reported Angus as the predominant breed in client herds and another 19\% (59/306) listed Angus as the second most common breed. Unregistered cow-calf operations (86\%; 275/319) were the most frequent type of herd served by veterinarians followed by registered commercial cow-calf (70\%), registered seedstock (59\%), and unregistered seedstock operations (34\%). Feedlot operations were clients of $57 \%(184 / 319)$ of veterinarians and 20\% (64/319) of veterinarians also had backgrounder, stocker or dairy clients.

\section{Burden of MAP infection}

Twenty-two percent (34/155) of producers reported having infected animals at the time of questionnaire completion. Mean prevalence reported by producers was $0.8 \%(0,0$, 10). The basis of estimation for the percentage of infected animals by producers was personal experience $(n=51)$, veterinarian's opinion $(n=51)$, and an extrapolation from local and regional data $(n=4)$. Of the producers who wrote free-text responses, 87\% (110/127) also mentioned a formal testing process as the basis for estimation. In tested herds, the mean reported apparent prevalence was $2 \%$ $(0,0,100)$. A total of $27 \%(27 / 100)$ of producers had at least one animal with clinical signs suggestive of JD during the previous year. The mean frequency of clinical animals calculated using the number of reported clinical animals divided by the herd size was less than $0.01 \%(0,0,0.2)$.

The odds of testing the herd for MAP and enrolling in a control program were lower for commercial cow-calf herds compared to other producer types. Relative to nonseedstock herds, seedstock herds had a higher percentage of test positive animals $(\mathrm{P}=0.005$, Table 3$)$, but a lower percentage of clinical cows $(\mathrm{P}=0.045)$. Compared to herds not enrolled in a control program, enrolled herds had a lower percentage of test positive cows $(\mathrm{P}<0.001)$ and a lower percentage of clinical animals $(\mathrm{P}<0.001)$. The mean producer estimated prevalence was higher in medium (50-149 head) and highest in large ( $\geq 150$ head) herds. Relative to small herds ( $<50$ head), the odds of having a clinical animal were 4 times higher $(\mathrm{P}=0.045)$ in medium and 7 times higher $(\mathrm{P}<0.001)$ in large herds.

The mean animal level prevalence in client herds as reported by veterinarians (practicing in the same 9 states as surveyed producers) was $5 \%(0,2,60)$. The mean percentage of client herds with at least one infected animal was $26 \%(0,10,100)$. The mean percentage of infected cows within infected herds was $9 \%(0.01,5,80)$ (Table 4$)$. The percentage of client herds with at least one infected cow was higher for JD certified veterinarians $(\mathrm{P}<0.001)$ and veterinarians that had performed a risk assessment $(\mathrm{P}=0.010)$. The methods used by veterinarians to derive these estimates were the number of animals with clinical signs suggestive of JD $(73 \%, 237 / 325)$, ELISA results $(52 \%, 169 / 325)$, fecal culture results $(31 \%, 103 / 325)$, and an extrapolation from regional or national data $(16 \%$, $51 / 325)$.

\section{Management and testing}

Although $95 \%$ of producers had tested their herds at least once, only $30 \%$ of producers with clinical animals in their herd tested purchased additions, 35\% weaned calves early from test positive dams, and $12 \%$ removed calves from JD suspect dams. Compared to veterinarians' perceptions, producers were less likely to cull cows with signs consistent with JD $(\mathrm{P}=0.003)$, but more likely to test purchased additions $(\mathrm{P}=0.007$, Table 5$)$. Veterinarians reported that only $8 \%$ of their clients tested purchased additions for JD.

Miscellaneous free-text comments from two producers indicated that they purchased only pre-tested cattle from trusted or test-negative herds. One producer not only tested every purchased addition but also segregated those animals for 6 months. Producers were not specifically asked about the disposition of cows with clinical signs consistent with JD, but three producers noted that they culled such animals. A producer also reported that all suspect cows were destroyed. Regarding the disposition of calves, one producer marketed calves from infected dams as feeder cattle rather than retaining them as replacements. Another producer raised replacement heifers separately until 3 years of age. One producer noted that breeders should be encouraged, if not required, to only sell bulls and replacement females that are from test-negative dams. Another producer had a strong belief that herd transmission is due to the reuse 
Table 3 Burden of Mycobacterium avium subspecies paratuberculosis infection in cow-calf operations reported by US beef cow-calf producers

\begin{tabular}{|c|c|c|c|c|c|}
\hline \multirow[t]{2}{*}{ Herd type } & \multicolumn{2}{|c|}{ Responses } & \multirow{2}{*}{$\begin{array}{l}\text { Median (IQR) of non } \\
\text { zero responses (\%) }\end{array}$} & \multirow{2}{*}{$\begin{array}{l}\text { Range of all } \\
\text { responses (\%) }\end{array}$} & \multirow[t]{2}{*}{$P^{a}$} \\
\hline & Total & Non-zeros & & & \\
\hline \multicolumn{6}{|l|}{ Prevalence } \\
\hline Seedstock & 86 & 17 & $2(1$ to 4$)$ & 0 to 10 & 0.381 \\
\hline Non-seedstock & 69 & 17 & $3(1.5$ to 5$)$ & 0 to 10 & \\
\hline Closed herds & 55 & 9 & 1 (0.5 to 4$)$ & 0 to 8 & 0.184 \\
\hline Open herds & 90 & 22 & $2.8(1.5$ to 5$)$ & 0 to 10 & \\
\hline Enrolled herds & 114 & 23 & 2 (1 to 4$)$ & 0 to 8 & 0.287 \\
\hline Not-enrolled herds & 41 & 11 & $4(1$ to 10$)$ & 0 to 10 & \\
\hline \multicolumn{6}{|l|}{ Clinical animals } \\
\hline Seedstock & 53 & 10 & 0.010 (0.006 to 0.017$)$ & 0 to 0.04 & 0.045 \\
\hline Non-seedstock & 44 & 16 & 0.013 (0.005 to 0.030$)$ & 0 to 0.2 & \\
\hline Closed herds & 32 & 8 & 0.007 (0.006 to 0.08$)$ & 0 to 0.031 & 0.883 \\
\hline Open herds & 59 & 15 & 0.014 (0.005 to 0.033$)$ & 0 to 0.2 & \\
\hline Enrolled herds & 67 & 13 & 0.011 (0.006 to 0.016$)$ & 0 to 0.111 & 0.011 \\
\hline Not-enrolled herds & 30 & 13 & 0.015 (0.006 to 0.029$)$ & 0 to 0.2 & \\
\hline \multicolumn{6}{|c|}{ Test positive animals } \\
\hline Seedstock & 80 & 13 & 1.5 (1 to 3 ) & 0 to 100 & 0.005 \\
\hline Non-seedstock & 55 & 21 & 2 (1 to 5$)$ & 0 to 100 & \\
\hline Closed herds & 49 & 10 & 1.1 (1 to 5.5 ) & 0 to 100 & 0.300 \\
\hline Open herds & 78 & 22 & 2 (0.8 to 5$)$ & 0 to 100 & \\
\hline Enrolled herds & 105 & 18 & 1.75 (1 to 4$)$ & 0 to 100 & $<0.001$ \\
\hline Not-enrolled herds & 30 & 16 & $1.8(0.9$ to 5.25$)$ & 0 to 100 & \\
\hline
\end{tabular}

${ }^{\mathrm{a}}$ Wilcoxon rank-sum test based on all responses.

Table 4 Burden of Mycobacterium avium subspecies paratuberculosis infection in cow-calf operations reported by the US cow-calf veterinarians

\begin{tabular}{|c|c|c|c|c|c|}
\hline \multirow[t]{2}{*}{ Respondent type } & \multicolumn{2}{|c|}{ Responses } & \multirow{2}{*}{$\begin{array}{c}\text { Median (IQR) of non } \\
\text { zero responses (\%) }\end{array}$} & \multirow{2}{*}{$\begin{array}{l}\text { Range of all } \\
\text { responses (\%) }\end{array}$} & \multirow{2}{*}{$P^{a}$} \\
\hline & Total & Non-zeros & & & \\
\hline \multicolumn{6}{|c|}{ Cattle infected with MAP in practice clientele } \\
\hline JD certified & 109 & 105 & $2(1-5)$ & $0-60$ & \multirow{2}{*}{0.483} \\
\hline Not certified & 162 & 154 & $2(1-5)$ & $0-30$ & \\
\hline Performed risk assessment & 111 & 109 & $2(1-5)$ & $0-50$ & \multirow{2}{*}{0.723} \\
\hline Did not perform risk assessment & 154 & 144 & $3(1-5)$ & $0-60$ & \\
\hline \multicolumn{6}{|c|}{ Client herds with animal(s) infected with MAP } \\
\hline JD certified & 110 & 106 & $20(5-50)$ & $0-100$ & \multirow{2}{*}{0.006} \\
\hline Not certified & 166 & 156 & $10(3-34)$ & $0-100$ & \\
\hline Performed risk assessment & 112 & 110 & $15(5-50)$ & $0-100$ & \multirow{2}{*}{0.010} \\
\hline Did not perform risk assessment & 158 & 146 & $10(2-50)$ & $0-100$ & \\
\hline \multicolumn{6}{|c|}{ Infected cattle within MAP infected client herd } \\
\hline JD certified & 107 & 107 & $5(3-10)$ & $1-80$ & \multirow{2}{*}{0.454} \\
\hline Not certified & 154 & 154 & $5(2-10)$ & $0.01-40$ & \\
\hline Performed risk assessment & 111 & 111 & $5(2-10)$ & $0.05-80$ & \multirow{2}{*}{0.268} \\
\hline Did not perform risk assessment & 143 & 143 & $5(3-10)$ & $0.01-70$ & \\
\hline
\end{tabular}

${ }^{a}$ Wilcoxon rank-sum test based on all responses. 


\begin{tabular}{|c|c|c|c|c|c|c|}
\hline Activities to control diseases: & Respondent & Yes & No & Odds ratio & $95 \% \mathrm{Cl}$ & $P^{a}$ \\
\hline \multirow{2}{*}{$\begin{array}{l}\text { Remove calves from dams suspected of being infected with MAP prior } \\
\text { to nursing }\end{array}$} & Producers & 3 & 23 & \multirow{2}{*}{1.33} & \multirow{2}{*}{0.37 to 4.80} & \multirow{2}{*}{0.64} \\
\hline & Veterinarians & 21 & 214 & & & \\
\hline \multirow{2}{*}{$\begin{array}{l}\text { Cull cows showing signs consistent with a diagnosis of Johne's disease } \\
\text { prior to testing }\end{array}$} & Producers & 15 & 7 & \multirow{2}{*}{0.48} & \multirow{2}{*}{0.18 to 1.26} & \multirow{2}{*}{0.154} \\
\hline & Veterinarians & 165 & 37 & & & \\
\hline \multirow{2}{*}{$\begin{array}{l}\text { Cull cows with signs consistent with a diagnosis of Johne's disease after } \\
\text { laboratory testing }\end{array}$} & Producers & 19 & 7 & \multirow{2}{*}{0.19} & \multirow{2}{*}{0.07 to 0.52} & \multirow{2}{*}{0.003} \\
\hline & Veterinarians & 240 & 17 & & & \\
\hline \multirow{2}{*}{$\begin{array}{l}\text { Cull calves from dams suspected or confirmed to be infected with MAP } \\
\text { based on testing or clinical signs }\end{array}$} & Producers & 15 & 9 & \multirow{2}{*}{1.44} & \multirow{2}{*}{0.60 to 3.46} & \multirow{2}{*}{0.419} \\
\hline & Veterinarians & 105 & 91 & & & \\
\hline \multirow{2}{*}{$\begin{array}{l}\text { Early weaning of calves from dams with positive results from } \\
\text { Johne's disease tests }\end{array}$} & Producers & 7 & 13 & \multirow{2}{*}{1.82} & \multirow{2}{*}{0.68 to 4.83} & \multirow{2}{*}{0.245} \\
\hline & Veterinarians & 45 & 152 & & & \\
\hline \multirow{2}{*}{$\begin{array}{l}\text { Cull cows without clinical signs consistent with a diagnosis of Johne's disease, } \\
\text { but positive serology (ELISA) }\end{array}$} & Producers & 14 & 8 & \multirow{2}{*}{1.96} & \multirow{2}{*}{0.79 to 4.88} & \multirow{2}{*}{0.153} \\
\hline & Veterinarians & 92 & 103 & & & \\
\hline \multirow[t]{2}{*}{ Test purchased additions for Johne's disease } & Producers & 6 & 14 & \multirow{2}{*}{5.19} & \multirow{2}{*}{1.77 to 15.24} & \multirow{2}{*}{0.007} \\
\hline & Veterinarians & 17 & 206 & & & \\
\hline
\end{tabular}

${ }^{a}$ Mid-point exact $P$ values.

of palpation gloves during pregnancy diagnosis. One producer also stated that their management and facilities were designed to control JD by elevating feed bunks and reducing stocking density within winter feeding areas.

The veterinarian $(n=277)$ recommended protocols for the initiation of a testing program in beef cow-calf herds were bacterial culture of feces (3\%), PCR (14\%), ELISA (35\%) and a combination of these tests $(47 \%)$. The recommended interval between testing was 12 months by $79 \%(198 / 252)$ of respondent veterinarians. Eleven percent (28/252) recommended testing every six months while one respondent recommended testing more frequently than 6 months. Three percent $(8 / 252)$ of veterinarians recommended 18 months, $7 \%(18 / 252)$ recommended a testing interval of more than 18 months, and 3\% (7/252) of respondents did not believe periodic testing was necessary. A total of $46 \%(124 / 270)$ of respondents preferred a combination of ELISAs with PCR or fecal culture for herds starting a testing program. Thirty-four percent (42/136) of respondents preferred a combination of tests based on the assumption that it would improve sensitivity, specificity or "accuracy". Thirty-six percent $(97 / 270)$ of veterinarians preferred ELISA because it is rapid (49\%, 48/97), inexpensive $(46 \%, 45 / 97)$, and convenient $(38 \%, 37 / 97)$ for whole herd screening.

\section{Discussion}

Seedstock producers that had a risk assessment for JD performed in their herds were more likely to be currently enrolled in a JD control program. This can be related to an overall awareness of seedstock producers concerning the importance of improved herd health for better economic outcomes. The mean value of animals in a seedstock herd is typically higher than those in commercial cow-calf operations. Seedstock producers were also more likely to purchase additions compared to non-seedstock producers and this increases the risk of introducing infected animals.

The producer estimated mean cow-level prevalence was $0.8 \%$. This was derived from the aggregation of their best estimate and is not necessarily based on previous test results. Similarly, a nationwide study estimated that $0.4 \%$ of US beef cattle were seropositive $[4,8]$. Other studies have reported a seroprevalence of 3\% [7], 5\% [6], and $9 \%[5]$ and this suggests that the true prevalence might be $7 \%$ to $28 \%$ after adjustment for the sensitivity and specificity of available serum ELISA [11]. Producers with infected herds (22\%) and the mean percentage of infected herds estimated by veterinarians (26\%) were lower than previous field studies. Forty percent of beef herds in Missouri [6], 44\% of herds in Texas [7], and $63 \%$ of herds in Alabama [5] have been reported as seropositive for JD. The perception that there is a higher percentage of infected herds by veterinarians with JD certification or risk assessment experience might be due to a better understanding of disease burden. Another possible explanation for this perception is that producers suspecting that their herd is infected might seek the services of a JD certified veterinarian. Some differences in perceptions are expected because published reports were based on seroprevalence, while respondents answered based on test results, regional or national data, and experience. Furthermore, veterinarians estimated the prevalence based on a typical client herd rather than the 
testing of a specific herd. The majority of producers had tested their herd, or a part of the herd in the past, but their responses were not necessarily an accurate representation of this test-based prevalence.

Commercial cow-calf producers included in this survey were less likely to be currently enrolled in a control program compared to producers without commercial cow-calf herds. Commercial cow-calf producers tended to maintain a herd with replacements obtained from within the herd itself (closed herd), which enables producers to minimize new infections from additions. A lower comparative prevalence in closed herds also suggests reduced probability of introduction of infected stock. In a previous study, only $25 \%$ of producers perceived significant financial and non-financial benefits associated with participation in the VBJDCP [17] and those results were from producers with an extremely low probability of having MAP infected cows (classification level 4). Although 84\% (46/55) of closed herds were already reported to be infected, maintaining a closed herd is an effective method to prevent further introduction of infected cows. Mixing replacement heifers from different production units without known low-risk status might increase exposure and chance of transmission from subclinically infected animals $[18,19]$. Excluding dairy cattle and ensuring more effective farm biosecurity will reduce the risk of introducing MAP infection into beef herds [20]. Strict biosecurity by not allowing infected cattle to enter the farm is the only necessary control measure for uninfected herds [21].

Compared to small herds $(<50$ head $)$, test-based prevalence and producers' estimate of the herd prevalence were higher in medium sized herds (50-149 head) and highest in large ( $\geq 150$ head) herds. The odds of having a cow with clinical signs of JD were higher in larger herds, possibly due to an increased probability of detecting rare events in larger herds. Larger herds might also be more likely to have a higher MAP infection prevalence because of an expected higher rate of animal movements and increased density of animals in areas where cattle congregate for feed, water, and shade [18]. Only 63\% (100/160) of producers answered the question concerning having a cow with clinical signs suggestive of JD during the previous year. The true percentage of herds with clinical animals might have been lower than estimated because producers who left the answer blank (handled as missing data) might have had no clinical animals. Most herds reported having only a single case during the previous year.

The number of producers employing herd testing was higher among those enrolled in a control program. Ninetyfive percent of herds were tested for MAP at least once although only $74 \%$ percent of producer respondents were currently enrolled in a control program. Disinclination from regular testing might be attributed to the low sensitivity of available tests [22,23]. One respondent producer commented that until a test is developed that is more than " $50 \%$ accurate" it would be "stupid and irresponsible" to perform the management practices proposed in the questionnaire. While it is true that test sensitivities are low, perhaps this illustrates that producers do not have an adequate understanding of test interpretation and the general importance of herd hygiene.

Responses from veterinarians regarding testing were mostly in favor of ELISA for herds starting a control program. Fecal culture is considered more sensitive and specific than ELISA [11,24] although it is costly and there is a long delay in the availability of results due to the slow growth of MAP in culture [25]. The majority of respondent veterinarians recommended a 12-month interval similar to the VBJDCP $[13,26,27]$. Specific client and herd needs might warrant a different test type and interval. One producer implemented 6-monthly intervals when testing was subsidized by the program. In Canadian dairy herds, ELISA-seropositivity was significantly associated with "open heifers purchased during the last 12 months" [28]. However, testing purchased additions was a preferred practice reported only by $30 \%$ of producers and $8 \%$ of veterinarians. One of the most important routes of transmission between herds is the addition of subclinically infected animals [18]. While producers in general appeared less concerned about infected replacements, one respondent tested and quarantined additions for 6 months. One of the reasons for not testing additions was that some producers only purchased animals from herds with known JD low-risk status. In Canada, veterinarians perceived that less than half of beef producers would prefer purchasing replacements from herds where a risk assessment had been performed [29].

The immediate removal of calves from an infected dam was only practiced by $12 \%$ of producers and perceived to be performed by $9 \%$ of veterinarians. Cow-to-calf transmission occurs most commonly within the calving area and early removal would be expected to reduce the risk of transmission [23,30]. Producers within the VBJDP are educated concerning possible routes of cow-to-calf transmission during enrollment into the program [27]. More than half of the responses from both producers and veterinarians favored culling calves based on a positive test or suspect clinical signs in the dam. While calves from test positive dams are reported to have lower weaning weights [31], one producer indicated that such calves can still be fattened and sent to slaughter, which would be economically more rewarding than immediate removal.

A major limitation of this study is that questionnaires were sent only to producers that had on-farm risk assessments performed and herd management plans developed. Also, 
the response proportions of $17 \%$ and $31 \%$ from producers and veterinarians, respectively indicates a possibility of non-response bias. The impact of these potential biases could not be assessed because information regarding nonresponders was not available. Comparability was attempted by recruiting producers and veterinarians from the same 9 states. However, it is possible that respondent veterinarians might not have served the specific producers included in this study. Only producers with clinical cows during the previous year were included in the analysis of disease control activities because such activities would not be applicable to JD-free herds. However, only 27 respondents reported having had clinical animals in their herd and this caused a lower precision in estimated measures of association.

The percentage of producers currently enrolled in a control program among the responders of this study $(75 \%)$ is quite high because the DJCs in each state contacted the producers that had risk assessments performed in their herds. Therefore, these producers presumably have more knowledge concerning JD than US beef producers in general. The power to detect significant associations was low for some variables and several significant associations might be counterintuitive. Seedstock producers were more likely to have uninfected herds even though they were more likely to introduce new animals onto their premises (maintain an open rather than closed herd). A possible explanation is that infected seedstock producers do not adopt a formal control program because they fear lack of confidentiality.

\section{Conclusions}

Seedstock producers that had JD risk assessments performed on their farms were more concerned with JD compared to other producer groups. These producers were less likely to have an infected herd and more likely to enroll in a control program despite the fact that they purchased additions more frequently than other producer categories. Testing purchased additions was not a popular practice. Serum ELISA based culling was also not common among producers that had clinical animals in the past. This is further supported by the fact that closed herds had a lower perceived prevalence, lower test positive percentage, and also a lower risk of having animals with clinical JD. Educational activities regarding better biosecurity measures and control of JD should be directed at larger herds since those were more likely to have test positive cows.

\section{Abbreviations}

JD: Johne's disease; DJC: Designated JD Coordinator is the person selected by the state animal health official and the Area Veterinarian in Charge; JD certified veterinarian: Accredited veterinarian that received additional training on JD epidemiology, sample collection, testing, test interpretation, state and federal program requirements, on-farm risk assessments, and herd management plan development.; MAP: Mycobacterium avium subsp. paratuberculosis;
VBJDP: US Voluntary Bovine Johne's Disease Control Program. This program was developed in cooperation with the National JD Working Group and the JD committee of the United States Animal Health Association, State Veterinarians and industry representatives. It was approved by the USDA's Animal and Plant Health Inspection Service (APHIS), Veterinary Services (VS). The Program was administered at the individual state level and supported by industry and the federal government.

\section{Competing interests}

The authors declare that they have no competing interests.

\section{Authors' contributions}

BB drafted the questionnaires, recorded the responses, analyzed the data, and prepared the manuscript draft. GTF, JBO, AJR and SCP participated in the design of both the questionnaires. AJR coordinated the design and deployment of both questionnaires. BB, GTF and JBO conducted the statistical analysis. All authors participated in development of the manuscript. All authors read and approved the final manuscript.

\section{Acknowledgements}

Funding for this study was provided by the Program for the Study of JD in Texas and by a cooperative agreement with USDA-APHIS-VS. We would like to thank Dr. Lisa Benjamin for her valuable feedback on the questionnaires, and state DJCs of FL, GA, IA, MO, ND, SC, SD, WI, and W for their help in administration of the producer questionnaires. We would also like to thank Dr. Charles P. Fossler for his valuable feedback on a preliminary version of this manuscript.

\section{Author details}

${ }^{1}$ Department of Veterinary Integrative Biosciences, Texas A\&M University, College Station, TX 77843, USA. ${ }^{2}$ Department of Production Animal Studies, University of Pretoria, Onderstepoort, South Africa. ${ }^{3}$ Zoetis, Kalamazoo, MI 49007, USA. ${ }^{4}$ Texas A\&M AgriLife Research and Extension Centre, Vernon, TX 76385, USA. ${ }^{5}$ Department of Large Animal Clinical Sciences, Texas A\&M University, College Station, TX 77843, USA. ${ }^{6}$ Current address: Institute of Biomedical Studies, Baylor University, One Bear Place, Box 97261, Waco, TX 76798, USA.

Received: 4 September 2013 Accepted: 3 January 2014

Published: 23 January 2014

\section{References}

1. Harris NB, Barletta RG: Mycobacterium avium subsp. paratuberculosis in Veterinary Medicine. Clin Microbiol Rev 2001, 14(3):489-512.

2. Chiodini RJ, Van Kruiningen HJ, Merkal RS: Ruminant paratuberculosis (Johne's disease): the current status and future prospects. Cornell Vet 1984, 74(3):218-262.

3. Manning EJ, Collins MT: Mycobacterium avium subsp. paratuberculosis: pathogen, pathogenesis and diagnosis. Rev Sci Tech OIE 2001, 20(1):133-150.

4. NAHMS: Info Sheet: What do I need to know about Johne's Disease in Beef Cattle? National Animal Health Monitoring System, Animal and Plant Health Inspection Service, United States Department of Agriculture; 1999 [http:// www.aphis.usda.gov/animal_health/nahms/beefcowcalf/downloads/beef97/ Beef97_is_Johnes.pdf]

5. Hill BB, West M, Brock KV: An estimated prevalence of Johne's disease in a subpopulation of Alabama beef cattle. J Vet Diagn Invest 2003, 15(1):21-25

6. Thorne JG, Hardin LE: Estimated prevalence of paratuberculosis in Missouri, USA cattle. Prev Vet Med 1997, 31(1-2):51-57.

7. Roussel AJ, Libal MC, Whitlock RL, Hairgrove TB, Barling KS, Thompson JA: Prevalence of and risk factors for paratuberculosis in purebred beef cattle. J Am Vet Med Assoc 2005, 226(5):773-778.

8. Dargatz DA, Byrum BA, Hennager SG, Barber LK, Kopral CA, Wagner BA, Wells SJ: Prevalence of antibodies against Mycobacterium avium subsp paratuberculosis among beef cow-calf herds. J Am Vet Med Assoc 2001, 219(4):497-501.

9. VBJDCP: How to Do Risk Assessments and Management Plans for JD. United States Animal Health Association, Johne's Committee; 2002 [http://www. tahc.state.tx.us/animal_health/johnes/RAs\&MPs_Dairy\&Beef_Herds.pdf] 
10. Benjamin LA, Fosgate GT, Ward MP, Roussel AJ, Feagin RA, Schwartz AL: Attitudes towards biosecurity practices relevant to Johne's disease control on beef cattle farms. Prev Vet Med 2010, 94(3-4):222-230.

11. Collins MT, Gardner IA, Garry FB, Roussel AJ, Wells SJ: Consensus recommendations on diagnostic testing for the detection of paratuberculosis in cattle in the United States. J Am Vet Med Assoc 2006, 229(12):1912-1919.

12. Carter MA: State, federal, and industry efforts at paratuberculosis control. Vet Clin N AM-Food A 2011, 27(3):637-645.

13. USDA: Uniform Program Standards for the Voluntary Bovine Johne's Disease Control Program. In vol. APHIS 91-45-014, Issued April, 2002 edn United States Department of Agriculture, Animal and Plant Health Inspection Service; 2002:25 [http://www.johnes.org/handouts/files/JD_ Program_Standards.pdf]

14. Bhattarai B, Fosgate GT: Increased response proportions for postal questionnaires in Texas veterinarians using incentives. Prev Vet Med 2010, 93(1):62-65.

15. Bhattarai B, Fosgate GT, Osterstock JB, Fossler CP, Park SC, Roussel AJ: Perceptions of veterinarians in bovine practice and producers with beef cow-calf operations enrolled in the US Voluntary Bovine Johne's Disease Control Program concerning economic losses associated with Johne's disease. Prev Vet Med 2013, 112(3-4):330-337.

16. Dean AG, Sullivan KM, Soe MM (Eds): OpenEpi: Open Source Epidemiologic Statistics for Public Health, Version 2.3.1. 2011 [www.OpenEpi.com]

17. Benjamin LA, Fosgate GT, Ward MP, Roussel AJ, Feagin RA, Schwartz AL: Benefits of obtaining test-negative Level 4 classification for beef producers in the Voluntary Bovine Johne's Disease Control Program. Prev Vet Med 2009, 91(2-4):280-284.

18. Sweeney RW: Transmission of paratuberculosis. Vet Clin N AM-Food A 1996, 12(2):305-312.

19. Kovich DA, Wells SJ, Friendshuh K: Evaluation of the Voluntary Johne's Disease Herd Status Program as a source of replacement cattle. J Dairy Sci 2006, 89(9):3466-3470.

20. Larsen JW, Webb Ware JK, Kluver P: Epidemiology of bovine Johne's disease (BJD) in beef cattle herds in Australia. Aust Vet $J 2012$, 90(1-2):6-13.

21. Roussel AJ: Control of paratuberculosis in beef cattle. Vet Clin N AM-Food A 2011, 27(3):593-598.

22. Wang C, Turnbull BW, Grohn YT, Nielsen SS: Estimating receiver operating characteristic curves with covariates when there is no perfect reference test for diagnosis of Johne's disease. J Dairy Sci 2006, 89(8):3038-3046.

23. Benedictus A, Mitchell RM, Linde-Widmann M, Sweeney R, Fyock T, Schukken YH, Whitlock RH: Transmission parameters of Mycobacterium avium subspecies paratuberculosis infections in a dairy herd going through a control program. Prev Vet Med 2008, 83(3-4):215-227.

24. van Schaik G, Pradenas FM, Mella NA, Kruze VJ: Diagnostic validity and costs of pooled fecal samples and individual blood or fecal samples to determine the cow- and herd-status for Mycobacterium avium subsp. paratuberculosis. Prev Vet Med 2007, 82(1-2):159-165.

25. Kudahl AB, Sørensen JT, Nielsen SS, Østergaard S: Simulated economic effects of improving the sensitivity of a diagnostic test in paratuberculosis control. Prev Vet Med 2007, 78(2):118-129.

26. USDA: Uniform Program Standards for the Voluntary Bovine Johne's Disease Control Program. In vol. APHIS 91-45-016, Effective November 1, 2005 edn. United States Department of Agriculture, Animal and Plant Health Inspection Service; 2005:28 [http://www.johnes.org/handouts/files/ USDAStandards11-05.pdf]

27. USDA: Uniform Program Standards for the Voluntary Bovine Johne's Disease Control Program. In vol. APHIS 91-45-016, Effective September 1, 2010 edn. United States Department of Agriculture, Animal and Plant Health Inspection Service; 2010:40 [http://www.aphis.usda.gov/animal_health/ animal_diseases/johnes/downloads/johnes-ups.pdf]

28. Tiwari A, Vanleeuwen JA, Dohoo IR, Keefe GP, Haddad JP, Scott HM, Whiting T: Risk factors associated with Mycobacterium avium subspecies paratuberculosis seropositivity in Canadian dairy cows and herds. Prev Vet Med 2009, 88(1):32-41.

29. Sorge US, Mount J, Kelton DF, Godkin A: Veterinarians' perspective on a voluntary Johne's disease prevention program in Ontario and western Canada. Can Vet J 2010, 51(4):403-405.
30. Windsor PA, Whittington RJ: Evidence for age susceptibility of cattle to Johne's disease. Vet J 2010, 184(1):37-44.

31. Bhattarai B, Fosgate G, Osterstock J, Fossler C, Park S, Roussel A: Comparison of calf weaning weight and associated economic variables between beef cows with and without serum antibodies against or isolation from feces of Mycobacterium avium subsp paratuberculosis. J Am Vet Med Assoc 2013, 243(11):1609-1615.

doi:10.1186/1746-6148-10-27

Cite this article as: Bhattarai et al:: Perceptions of veterinarians and producers concerning Johne's disease prevalence and control in US beef cow-calf operations. BMC Veterinary Research 2014 10:27.

\section{Submit your next manuscript to BioMed Central and take full advantage of:}

- Convenient online submission

- Thorough peer review

- No space constraints or color figure charges

- Immediate publication on acceptance

- Inclusion in PubMed, CAS, Scopus and Google Scholar

- Research which is freely available for redistribution 